While I have noted some quibbles in this review, they are all really quite minor complaints. Audubon Alaska, and especially Daniel Huffman, have achieved the goals laid out in the Introduction, and they can all be proud of this beautiful atlas.

\title{
PATENTS AND CARTOGRAPHIC INVENTIONS: A NEW PERSPECTIVE FOR MAP HISTORY
}

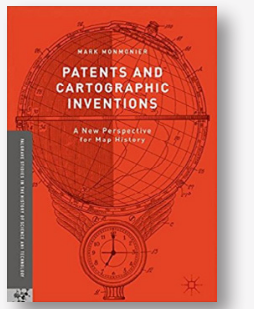

\author{
By Mark Monmonier \\ Palgrave Macmillan, 2017
}

267 pages, \$109.99, hardcover.

ISBN: 978-3-319-51039-2

\section{Review by: John J. Swab, University of Kentucky}

Mark Monmonier makes a significant contribution to the contextualization of recent cartographic history with his new book Patents and Cartographic Inventions: A New Perspective for Map History. Focused on cartographic innovations approved for patents by the United States Patent and Trademark Office, the book weaves together the fascinating stories of the individuals who developed new mapping technologies from the mid-nineteenth century to the pre-digital twentieth century. Monmonier sees cartographic patents as a little-explored, "parallel literature" to academic cartographic scholarship (6). He proposes that the patent system, with a similar peer-review-like process conducted by patent examiners, provides both a methodological and metaphorical lens through which to understand cartographic innovations over the past century and a half.

The book is organized around thematic chapters examining innovations in identifying locations, wayfinding systems, map folding systems, map projections, novel globes, and a variety of other pre-digital cartographic topics. It examines how the inventions in each of these subthemes built upon both real-world challenges and previously submitted patents, while also detailing the larger stories behind the individual inventors and their adventures navigating the patent application process. As Monmonier's research uncovers, many of these patented innovations were useful and innovative technological developments, even if most were commercially unsuccessful.

While it may be common to believe that georeferencing technologies were only developed recently, as part of the geospatial revolution, an examination of patent records finds antecedents throughout the early twentieth century. For example, multiple patents addressed wayfinding systems that provided nuanced geographic information to aid travelers to reach their destination. Rolled strip maps, advanced by the revolution of car wheels or by hand, were among the first GPS-like technologies. Rural homestead finding systems, developed and sold from the 1910s to the 1930s, provided specially designed maps to aid visitors in locating specific farmsteads down poorly marked country roads.

Other types of inventions, such as those related to map projections or folding systems, were often far less commercially successful. Here, Monmonier contends, it was often more effective to simply use copyright law than to struggle through the patent application process. The important role played by patented paper folding machines (in developing novel ways to fold maps) is touched upon as an example of how innovations in other technologies can lead to new patentable inventions in the cartographic realm. Patent applications for new globes often stressed their educational qualities, with patents filed to protect innovations in mechanical globes highlighting atmospheric phenomena or orbital patterns. With the vast majority of patent applications filed by men, it is notable how the gendered nature of education played out with a relatively large number of globe patents issued to female inventors.

As the book recounts in example after example, winning approval from the United States Patent Office was (and still is) an arduous, time-consuming affair. Applications often languished for years, as examiners, inventors, and lawyers haggled over the meaning of descriptions, redrew poorly executed drawings, and bickered over sweeping technical claims. In practice, this often meant that applications took long periods of time, involving multiple rounds of revisions before finally receiving approval. Occasional grandstanding on the part of the inventor, the patent lawyer, and/or the patent examiner often led to ultimatums, fraught responses, and desperate appeals for leniency. 
However, since Monmonier studied only approved patents it is difficult to understand how often and in what ways this review process may have failed. Normally, the approval process was a game of persistence and patience, in which the patent examiner and inventor would spar over individual claims until one side conceded (or modified the claims) and the patent was approved. Monmonier jokingly compares the patent process to the standard academic writing process in which "a stubbornly unwavering author can wear down a reluctant editor" (17).

In some regards, the importance of these patents to the historical cartographic record is questionable. Ultimately, most of the patents filed were never commercially viable, and generally very few physical examples have survived, arguably indicating a lack of widespread use. While some, such as the patented Van der Grinten projection used for the National Geographic Society's logo or the circular route indicators for early automobiles, were widely used, the broader impact of these patents is not always discussed. This is not due to any shortcoming in Monmonier's research, but rather to two specific factors. The first deals with the limited importance of the innovations-in other words, not all patents were commercially feasible and thus were limitedly distributed. The second involves the motives and circumstances of the inventor themselves-an inventor could patent any innovation, but the process of financing large-scale production and marketing held back ideas that could have been profitable under the right circumstances. Certainly the patent literature, especially that discussed in the book's last chapter on the transition to digital mapping, provides some inspiration for future inventors. However, except where there are direct citations of earlier patents in a new application, tracing this intellectual history is difficult.

While patents have long been a vehicle for financial gain (either through manufacture or by selling the intellectual rights to someone who can build the product), in recent years other tactics have provided an increasingly lucrative means of profiteering from inventions. Patents and Cartographic Inventions touches on the practices of individuals who file or purchase patents solely for the purpose of keeping innovations out of the hands of competitors and on actual patent trolls who purchase patents merely to bring litigation against competitors. Monmonier's brief discussion in the final chapter opens the door to a much deeper analysis that will be needed to fully understand the impacts of this relatively recent phenomenon.
Although one can argue that cartographic patents are a parallel literature to academic and professional literatures, the linkages between the two are not very clear. Addressing this Monmonier discusses the "theory of multiples," in which multiple, unconnected individuals develop similar innovations in a short time period (14). A key concept in the field of patent studies, the theory connects concurrent innovations with the emergence of similar solutions to different problems to contextualize why similar innovations cluster together temporally while often being dispersed geographically. Most of the chapters include one or more specially designed diagrams classifying patents by their primary technical aims and approval date. Although these diagrams are fascinating, and show the near-constant filing of cartographic patents, the text itself does not fully tie the body of patent literature to mainstream cartography during the nineteenth and twentieth centuries. Apart from an extensive, seven-page discussion of map folding methods in twentieth-century cartographic literature, most other developments are not well connected with applied cartography.

The National Science Foundation grant that Monmonier received to undertake this research placed particular emphasis on how inventors ultimately conceive and patent their innovations. The end result of this research is a wealth of biographical information on individual inventors. Unsurprisingly, the vast majority of examined inventors were Americans, although relevant international connections are made throughout the book. The volume of biographical detail can be a bit excessive at times-as are some of the liberties taken in making connections between different events (a point readily addressed by Monmonier in the Preface). Additional information regarding the biographical details of cartographic innovators-including many not covered in Patents and Cartographic Inventionscan be found in the recently published companion book entitled A Directory of Cartographic Inventors (Monmonier et al. 2018).

In terms of its construction, Patents and Cartographic Inventions is put together well. Illustrations are numerous and are often pulled from images available in the individual patent applications located in the National Archives or from the Official Gazette of the United States Patent Office - the government publication documenting newly issued patents since 1872. The images themselves are of high quality and are full page when needed, which greatly assists in making the details of the drawings legible. 
Interestingly, the book is organized for individual chapter downloads directly from the publisher's website which means that citations are located after each chapter, a practice which makes searching for references easier. The end matter is similarly well constructed with a comprehensive index and a very informative appendix on how to search for patents. The only limitation in book construction is the lack of a comprehensive list of figures and diagrams, which can make searching for a specific image time consuming.

Coming in at a whopping $\$ 109.99$ for the printed book, $\$ 84.99$ for the eBook version, and $\$ 29.99$ for individual eChapters, this is by no means an inexpensive book (although, as of writing, the printed book can be purchased for just over half-price on Amazon). However, for its niche topic, and in view of the dearth of other literature on cartographic patents, it is sure to become an essential read for those interested in this area of cartographic history. As such, it is an important acquisition for map libraries, those interested in the history of cartography, and scholars in science and technology studies.

In the end, Monmonier's book provides a much-needed, in-depth, and deeply researched analysis of cartographic patents. Patents and Cartographic Inventions: A New Perspective for Map History is recommended for those interested in understanding how cartographic innovations have developed over the past century and a half.

\section{REFERENCE}

Monmonier, Mark, Adrienne L. Atterberry, Kayla Fermin, Gabrielle Marzolf, and Madeline Hamlin. 2018. A Directory of Cartographic Inventors: Clever People Awarded a US Patent for a Map-Related Device or Method. Syracuse, NY: Bar Scale Press.

\section{OXFORD ATLAS OF THE WORLD, TWENTY-FOURTH EDITION}

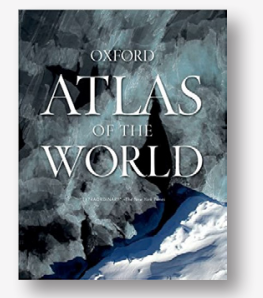

Oxford University Press USA, 2017

448 pages, $\$ 89.95$, hardcover.

ISBN: 978-0-19-084362-5

\section{Review by: Tanya Buckingham, University of} Wisconsin-Madison

The blurb on the back cover of the Oxford Atlas of the World boasts that it is "the only world atlas to be updated annually," which, incidentally, means that this review of the twenty-fourth edition, copyright 2017, should appear just barely before the twenty-fifth is released. The review begins with an inventory of the twenty-fourth edition, and is followed by a comparison with the 2016 (twenty-third) and 2014 (twenty-first) editions. A comparison to last year's offering was an obvious choice, and a look back at the twenty-first was added for two reasons: first as a point of reference as to how much the atlas has changed, and second because that edition had also been reviewed for Cartographic Perspectives (Denil 2016).

The physical copy of the atlas provided for this review is a solid, hard cover book containing 448 thick, glossy, pages. It weighs 7.4 pounds, measures 14.6 inches $\times 11.4$ inches and is 1.4 inches thick. This edition of the Oxford Atlas of the World was published on November 1, 2017.

Opening the front cover, the reader is greeted with a world map on the endpapers. The cool color scheme of greens, blues, and greys in the twenty-fourth edition is quite different from the corresponding maps in the twenty-first and twenty-third editions, which sported a wider range of hues. The colors employed to indicate the extent, scale, and page number of each of the various atlas maps remain in the same groups, but are now tertiary, rather than primary, colors. One would expect that their brightness, in contrast to the new, more subdued background, would make them stand out better than they did in the previous edition, where they had more visual competition. I don't find this to be the case, myself, but perhaps the change was made to accommodate users with color vision impairments (a condition I lack). The legends to the world, city, and physical maps are all found on the opening endpaper as well.

The atlas maintains a consistent format across its recent editions, opening with a two-page "Foreword" spread, then a "User Guide," followed by the "Table of Contents." "World Statistics" comes after that introductory material, and provides an alphabetical listing of countries along with 